\title{
Microbial Contamination of Mobile Phones a Potential Threat to the Patients: A Cross Sectional Study
}

\author{
Shazia Naaz, K. Madhavi", Kiran Mai and Rajive K. Sureka \\ Department of Microbiology, MediCiti Institute of Medical Science, Hyderabad, \\ Telangana, India \\ *Corresponding author
}

\begin{abstract}
Keywords
Mobile phones, Microbial contamination, Health Care associated infections

\section{Article Info}

Accepted:

10 December 2018

Available Online:

10 January 2019 nosocomial infections. This study aimed to describe the role of the cell phones in transmitting bacteria to dominant hands of the HCW's in the various ICU's as MediCiti Institute of Medical Sciences, emphasizing the role of mobiles in the spread of HAI. It was a cross-sectional study including HCW's at various ICU's in our hospital. Samples for culture and sensitivity were collected from the dominant hand and the mobile phones of each study participant and were processed according to standard guidelines. Questionnaire about mobile phone usage, hand hygiene and disinfection practices were administered and assessed. $30 \%$ of the study participants never cleaned their mobile phones. The most common bacterial isolate from the hands were Staphylococcus aureus (44\%) and coagulase negative Staphylococcus (CONS - 36\%), while from cell phone swabs were similarly S. aureus (43\%) and CONS (36\%). The MRSA isolates from hands and cell phone were $33 \%$ and $17 \%$ respectively. Gram- negative bacteria were isolated from $15 \%$ of the hand swabs and $7 \%$ of the mobile swabs respectively. On sensitivity testing, 34\% and $25 \%$ of these GNB from hand and mobile were ESBL producers. Simple measures like hand washing, cleaning of mobile phones with $70 \%$ isopropyl alcohol and a well-practiced infection control plan to bring down the rate of hospital acquired infections are recommended.
\end{abstract}

\section{A B S T R A C T}

Mobile communication devices help accelerate the hospital flow of medical information but can serve as a "foe" for the patients when they act as a potential vector for transmitting

\section{Introduction}

Health care associated infections (HCAI) are amongst the most common avoidable complications of healthcare - leading to increased morbidity and mortality.

WHO states "At any given point of time the prevalence of HCAI ranges between 5.7\% $19.1 \%$ in low - middle income countries"
(Health care-associated infection FACT SHEET-WHO).

India presents an unnerving incidence rate ranging from $4.4-83 \%$ pertaining to various HCAI's (Ramasubramanian et al., 2014). As early as 1861 Semmelweis demonstrated that bacteria were transmitted to the patients by contaminated hands of HCW's (Ulger et al., 2009). 
Hand hygiene is one of the most important preventive interventions against the spread of infection in the Health Care setting (Heyba et al., 2015). Mobile phones (MP's) are devices that help to accelerate the flow of medical information and contribute to communication in case of emergencies.

Telecom \& Regulatory authority of India (TRAI 2018) reported that the number of telephone subscribers in India increased from 115.35 crore at the end of May 2018 to 116.88 crore at the end of June 2018 thereby showing a monthly growth rate of 1.33 per cent.

Mobile phones are used in close contact with the body and as for most non - medical electronic devices, there are no cleaning protocols available in developing countries like India, that meet the hospital standards (Shaktivel et al., 2017).

Places like ICU's require highest hygiene standards. In such critical settings such as ICUs the prolific use of such devices proves to act as a "double edged sword". It may serves as a "foe" for the patient by acting as a niche for harbouring bacteria to due constant handling and heat generation by device and be responsible for transmitting HCAIs.

The present study was aimed to describe the role of mobile phones in transmitting bacteria to the dominant hand and vice versa in various ICU's and to determine their role in the spread of HCAI's at a rural teaching hospital in Medchal district, Telangana.

\section{Materials and Methods}

\section{Study design}

The present study was a cross sectional study conducted at Medi Citi Institute of Medical Sciences, Medchal, Telangana - September 2018.

\section{Sample size}

We screened $50 \mathrm{HCW}$ 's posted at that point of time at various ICUs namely PICU, NICU, MICU, SICU. Informed consent was obtained from each participant. Questionnaire about mobile phone usage, hand hygiene, and disinfectant practices was administered and assessed.

\section{Inclusion criteria}

All resident doctors, nurses, interns posted in various ICUs at that point of time.

\section{Exclusion criteria}

Those HCWs not involved in mobile phone usage in ICUs and the cell phones that have been disinfected recently were excluded.

\section{Sample collection}

Two swabs were collected, one from the mobile phones and the other from the dominant hand of the $\mathrm{HCW}$ after taking consent. The mobile phone was first held in a sterile gloved hand and samples were collected using sterile swabs moistened with normal saline by rotating and swabbing over the screen, sides, external cover surface of the mobile phones. None of the mobile phones had a separate keypad as all those screened were Smartphone's.

The other swab which was also moistened with normal saline was used to swab the ventral surface of the dominant hand including the finger tips. Samples were properly labelled and sent to the Microbiology department for further processing.

\section{Sample processing at the laboratory}

The collected samples upon reaching the microbiology lab were immediately inoculated 
onto Blood agar and MacConkey agar. The plates were incubated at $35-37{ }^{\circ} \mathrm{C}$ for $24 \mathrm{hrs}$ and observed for growth. Growth of the bacteria was identified studying the colony morphology, gram stain, and by other standard biochemical reactions. Antibiotic sensitivity testing of isolates was done by Kirby- Bauer disc diffusion methods according to Clinical and Laboratory Standard Institute (CLSI) guidelines.

\section{Results and Discussion}

This study revealed that out of a total of 50 mobile phones and hands screened for microorganisms, $75 \%$ and $86 \%$ of the mobile and hand swabs respectively showed growth of various pathogenic bacteria.

These findings are similar to other studies where mobile phone and hand contamination rates were reported as follows Chandigarh (Post Graduate Institute Of Medical Education \& Research - PGIMER) - 28.57\% and 91.7\%, Ethiopia $-62 \%$ and $78 \%$, Uttarakhand- $81.8 \%$ and 80.8\%, (Malhotra et al., 2018; Chaka et al., 2016; Pal et al., 2015).

The distribution of major pathogenic isolates from mobile phones and hands of $\mathrm{HCW}$ has been presented in Table 1. The commonest isolate identified from both the mobile phones and the hand was Staphylococcus aureus (S.aureus) - 43\% and 44\% followed by Coagulase negative Staphylococcus aureus (CONS) $-36 \%$ respectively.

Similar findings were seen in studies conducted at Chandigarh - S. aureus and CONS from mobile phones were $31.25 \%$ and $25 \%$ respectively and S.aureus and CONS isolated from hands being $47 \%$ and $37.25 \%$ respectively- (Malhotra et al., 2018, PGIMER). Study done at Ethiopia reported similar findings with $S$. aureus and CONS from mobile phones being $59 \%$ and $37 \%$ respectively and $S$. aureus and CONS isolated from hands being $56 \%$ and $20 \%$ respectively (Chaka et al., 2016).

On the other hand study done at Uttarakhand, Iran (Bhumbala et al., 2016; Haghbin et al., 2015) found CONS as the most common isolate from both mobile phones and the hands of HCW's. This difference may be due to difference in colonization of individuals in separate geographical areas.

Bacterial contamination of the hand and mobile phones by the same organism was seen in 33 swabs $(66 \%)$. Study done at Ethiopia and Turkey showed the rates of cross contamination of hands and mobiles were similar by the same organism (Chaka et al., 2016; Ulger et al., 2009) Bhat et al., (2011) also reported similar isolates from mobile phone and hands.

Study done at PGIMER and Turkey (Malhotra et al., 2018; Ulger et al., 2009) reported rate of cross contamination of hands and mobile phones by similar organism was $7.14 \%$ and $33.3 \%$. Study done at PGIMER reported a low rate of mobile contamination, and so also lower rates of cross contamination probably due to rules restricting the usage of mobile phones inside the hospital. Similar reasons may be responsible for obtaining lower cross contamination rates in study done at Turkey.

Highest rate of contamination by the same organism on the mobile phones and the hands was amongst interns (100\%) followed by residents $(65 \%)$. These findings have been depicted in Figure 1.

The antibiotic sensitivity pattern revealed that $33 \%$ and $17 \%$ of the isolates obtained from hand and mobile phones of the HCW were Methicillin resistant Staphylococcus aureus (MRSA). These results have been shown in Figure 2. 
These findings are in concordance with other studies showing percentage of MRSA from mobile phones and hand swabs as - Ethiopia $-40 \%$ in both mobile phones and hand swabs respectively (Chaka et al., 2016), Turkey 52\% and $37.7 \%$ (Ulger et al., 2009).

Rate of mobile contamination with MRSA was high in the study done at Turkey which may be due to lower rates of decontamination of mobile phones and frequent usage in high risk settings in the hospitals.

In the present study, $34 \%$ and $25 \%$ Gram negative bacilli (GNB) isolated from hand and mobile phone swabs respectively were ESBL producers, shown in Figure 3.

Similar findings were reported by study done at Peru - 33\% ESBLs from mobile phone swabs (Loyola et al., 2017), and study done at Turkey $-39.5 \%$ and $31.3 \%$ ESBLs from hand and mobile swabs respectively (Ulger $e t$ al., 2009).

On the contrary, EBSL isolated from mobile phones was lower in studies conducted at Uttarakhand - 9.1\% and Turkey- $11.2 \%$ (Bhumbala et al., 2016; Ustun et al., 2012).

Table.1 Distribution of major pathogens isolated from hands and mobile phone of HCW's

\begin{tabular}{|l|l|l|}
\hline Major pathogens isolated & $\begin{array}{l}\text { Hands of the } \\
\text { HCWs } \\
\mathbf{n}=\mathbf{4 3}\end{array}$ & $\begin{array}{l}\text { Mobiles of HCWs } \\
\mathbf{n}=\mathbf{3 7}\end{array}$ \\
\hline Staphylococcus aureus & $19(44 \%)$ & $16(43 \%)$ \\
\hline CONS & $15(36 \%)$ & $13(36 \%)$ \\
\hline GRAM NEGATIVE BACTERIA & $9(21 \%)$ & $4(10 \%)$ \\
\hline OTHERS & - & $2(5.4 \%)$ \\
\hline
\end{tabular}

Table.2 Distribution of usage of Mobile Phones by various HCW's in the ICU

\begin{tabular}{|c|l|l|l|l|}
\hline HCW & $\begin{array}{l}\text { Total } \\
\mathbf{n = 5 0}\end{array}$ & $\begin{array}{l}\text { Profession } \\
\text { Resident }\end{array}$ & Nurses & Interns \\
\hline 1. $\begin{array}{l}\text { USE OF MOBILE } \\
\text { PHONE WHILE } \\
\text { WORKING IN ICU }\end{array}$ & $22(45 \%)$ & 15 & 2 & 5 \\
\hline
\end{tabular}

Fig.1 Cross contamination of mobile phones and hands by same organism

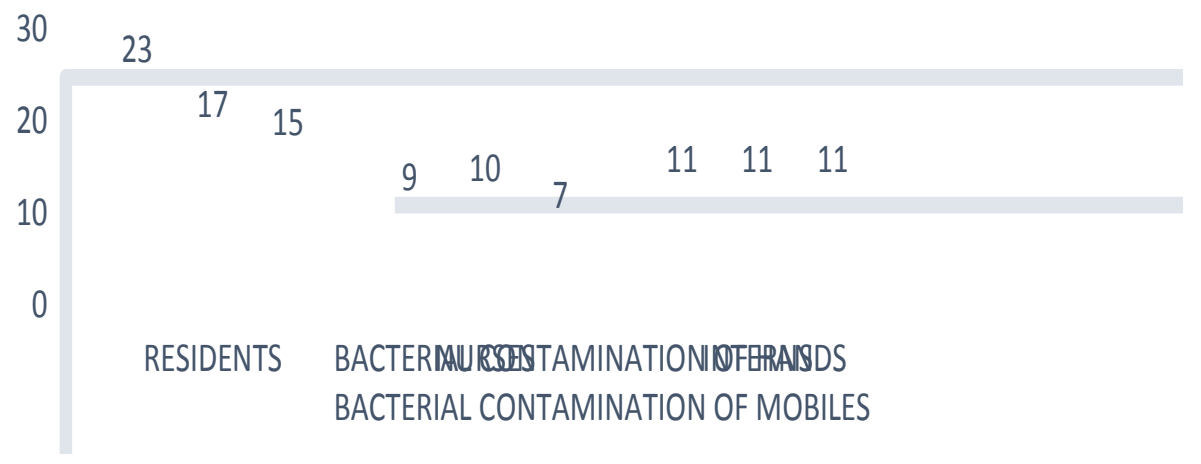


Fig.2 Distribution of MRSA from hands and Mobile phones of HCWs

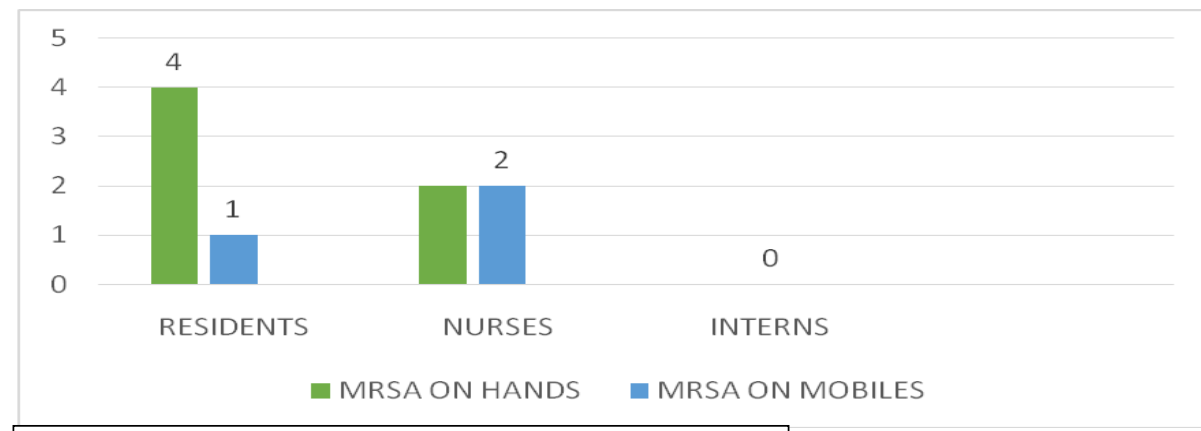

MRSA - HANDS - 6/19 (33\%)

MRSA - MOBILES - 3/16 (17\%)

Fig.3 Distribution of ESBL producing gram negative bacteria

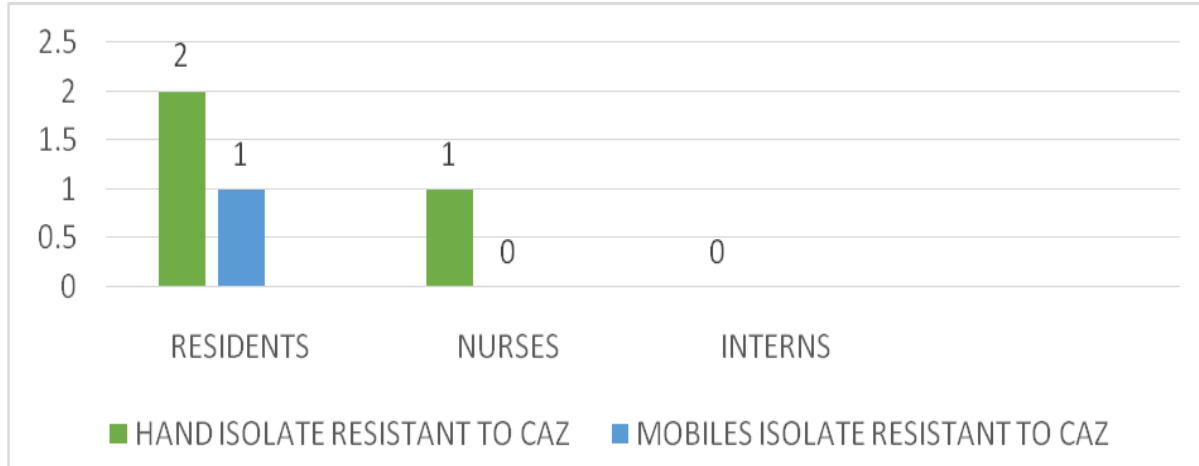

CAZ - Ceftazidime.

ESBL producers - hand - 3/9 (34\%). ESBL producers - mobiles - 1/ 4 (25\%)

Fig.4 Frequency of cleaning of Mobile phones by HCW's

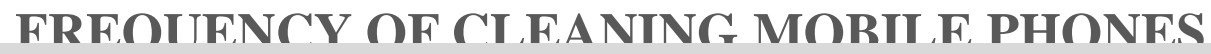

MONTHLY

$40 \%$
$0 \%$

NEVER CLEAN

$30 \%$ 
Fig.5 Various Disinfectants used for cleaning the Mobile phones

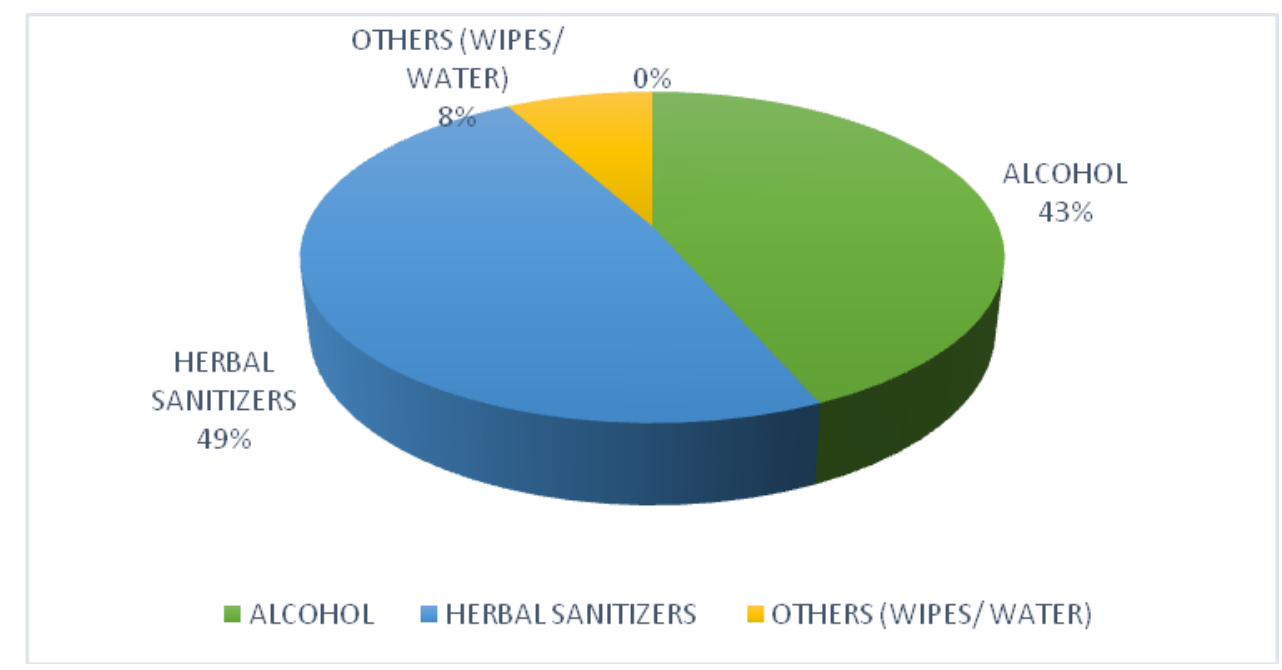

Fig.6 Hand hygiene compliance amongst HCW's

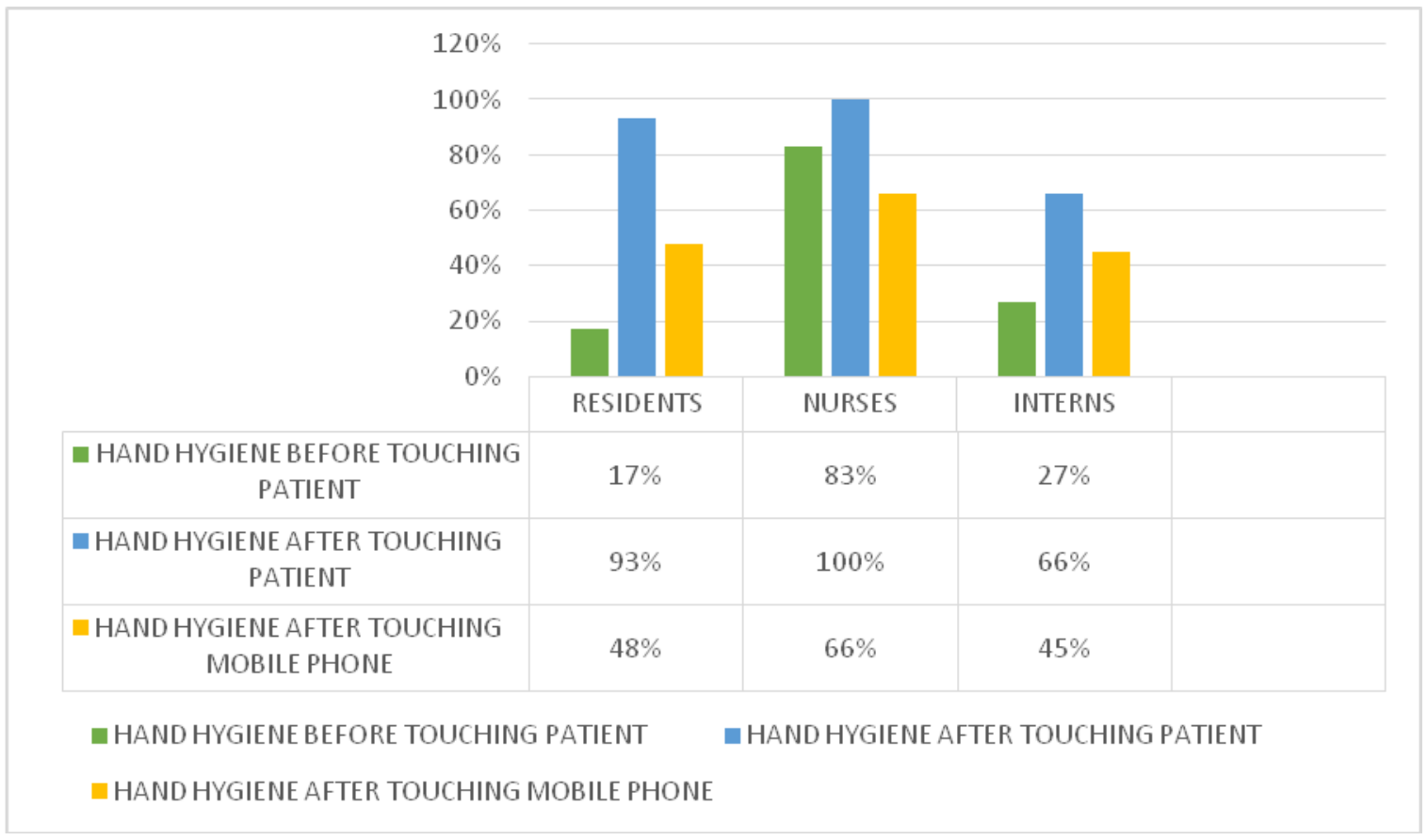

The isolation of MRSA and ESBL Klebsiella pneumoniae is a matter of concern. It proves the pathogenic potential of the organisms isolated from mobile phones and highlights the risk of mobile phones as vehicles of transmission of serious multiple drug resistant pathogens (Hadir EL-Kady, 2017).

\section{Questionnaire analysis}

Questionnaire analysis revealed maximum usage of mobile phone in the ICUs was by residents followed by interns use of mobile phone while working in the ICUs by various HCW has been shown in Table 2 . 
The frequency of cleaning of mobile phones and the usage of disinfectants for cleaning of mobile phones by various HCW's has been depicted in figure 4 and $5.30 \%$ reported never cleaning their mobile phones. $36 \%$ reported using alcohol based disinfectant to clean their mobile phones.

Maximum hand hygiene compliance was seen in amongst nurses and least amongst interns. Figure 6 shows compliance to hand hygiene practices amongst the HCW's. Hand hygiene before and after touching the patient were $44 \%$ and $90 \%$ respectively. Hand hygiene observed after touching the mobile phones was $15 \%$.

Study done at Tamil Nadu reported 100\% HCW's were using their mobile phones. $10 \%$ were using alcohol based rubs to disinfect their mobile phones. $12 \%$ washed their hands after using their mobile phones. 50\% HCW's wash their hands before attending the patients (Shakhtivelet al., 2017).

Study done by Cleveland (Canales $\mathrm{M}$ et al., 2017) mentioned usage of alcohol based rubs to clean their mobile phones was $34 \%$. $6 \%$ washed their hands after touching their mobile phones.

Their findings were in concordance to the Present study.

On the other hand study done at Saudi Arabia and Ethiopia reported $76 \%$ and $85 \%$ of their HCW's never cleaned their mobile phones. The usage of alcohol based rubs to clean the mobile phones was quoted as $12.4 \%$ and $19 \%$ respectively. These rates show the high propensity of contamination which may lead to a predisposition to HCAI's.

Manning el at (2013) suggested infection prevention (IP) bundles for mobile phones inclusive of water proof case for mobile phone, disinfecting mobile phone before and after visiting the patient, setting an alarm on the mobile as reminder for disinfecting it and observing hand hygiene before patient interaction and after disinfecting mobile phone.

To conclude our study reveals Participants hands and mobiles were contaminated with various types of bacteria.

Percentage of similar organisms isolate from mobiles and dominant hand was as high as $66 \%$, implying correlation in the transfer of microorganisms from mobile to hand and vice versa.

Everyday use of mobile phones by HCWs in critical care areas represents an important vehicle- may be capable of causing HCAIs. Awareness programmes must be conducted to create cognizance amongst the HCWs of the importance of infection control measures. Strict adherence to hand hygiene practices. Creating a protocol in hospitals to cleanse mobile phones using alcohol based disinfectant/ UV sterilizing unit would help in reducing the burden of HCAIs.

\section{References}

Bhat, S.S., Hegde, S.K., Salian, S. 2011.Potential of mobile phones to serve as a reservoir in the spread of nosocomial pathogen. Online $J$. Health Allied Sci., 10 (2): 14.

Bhumbala, U., Ahmad,S.M., Mathur D.R., Bandey, L, Gyaneshwari. 2016. Study on microbial contamination of mobile phones and their role in nosocomial infections in a tertiary hospital of South India. Asian J Pharm Clin Res, Vol 9, Suppl. 3, 201-20

Canales, M., Craig G., Boyd J., Markovic M., Chmielewski R. 2017. Dissemination of Pathogens by Mobile Phones in a 
Single Hospital, JISRF Level A, Volume 7, Number 3.

Chaka, T.E., Misgana, G.M., Feye, B.W. and Kassa, R.T. 2016. Bacterial Isolates from Cell Phones and Hands of Health Care Workers: A Cross Sectional Study in Pediatric Wards at Black Lion Hospital, Addis Ababa, Ethiopia. J. Bacteriol. Parasitol., 7:4.

Clinical and Laboratory Standards Institute. 2014. Performance standards for antimicrobial susceptibility testing; Twenty-fourth informational supplement, M100-S24. Wayne, PA: CLSI.

Hadir EL-Kady. 2017. Microbial Contamination of Mobile Phones in the Medical Laboratory Technology Department of a Private University in Alexandria, Egypt. Int.J.Curr. Microbiol.App.Sci 6 (6): 200-211.

Haghbin, S., Pourabbas, B., Serati, Z., Alborzi, A. 2015. Bacterial contamination of mobile phones and pens in paediatrics and neonatal intensive care units. Int.J.Curr.Microbiol.App.Sci (2015) 4(2): 75-81

Heyba, M., Ismaiel, M., Alotaibi, A., Mahmoud, M., Baqer, H., Safar, A., and Al-Taiar, A. 2015 . Microbiological contamination of mobile phones of clinicians in intensive care units and neonatal care units in public hospitals in Kuwait. BMC Infect Dis 15 (1): 434.

Loyola, S., Gutierrez S., Avendaño, E., Severino, N., Tamariz, J. 2018. Multidrug-resistant bacteria isolated from cell phones in five intensive care units: Exploratory dispersion analysis. Germs. Jun; 8 (2): 85-91.

Malhotra, S., Saini,V., Kaur,A.,Rawat, Y.2018.Bacterial Flora of Mobile Phones and Hands of HCWs from a Tertiary Care Hospital, BAOJ Microbiol., 4: 1

Manning, ML., Davis, J., Sparnon, E., Ballard RM. 2013. iPads, droids, and bugs: Infection prevention for mobile handheld devices at the point of care. Am J Infect Control.41 (11):1073-6.

Pal, S., Juyal, D., Adekhandi S. 2015 Mobile phones: Reservoirs for the transmission of nosocomial pathogens,Adv Biomed Res. 4: 144.

Shakthivel, P.C.G., Velvzhi G., Sucilathangam G., Revathy C. Mobile Phones in Healthcare Setting: Potential Threat in Infection Control. Int.J.Curr.Microbiol.App.Sci 6 (3): 706-711. https://www.trai.gov.in/ release-publication/reports/telecomsubscriptions-reports

Ulger, F., Esen, S., Dilek, A., Yanik, K., Gunaydin, M., and Leblebicioglu, H. 2009. Are we aware how contaminated our mobile phones with nosocomial pathogens? Ann Clin. Microbiol. Antimicrob., 8 (1): 7

Ustun, C. and Cihangiroglu, M. 2012. Health care workers' mobile phones: a potential cause of microbial cross contamination between hospitals and community. J Occup Environ Hyg 9 (9):53842. http://www.who.int/gpsc/ country_work/gpsc_ccisc_fact_sheet_ en.pdf

\section{How to cite this article:}

Shazia Naaz, K. Madhavi, Kiran Mai and Rajive.K.Sureka. 2019. Microbial Contamination of Mobile Phones a Potential Threat to the Patients: A Cross Sectional Study. Int.J.Curr.Microbiol.App.Sci. 8 (01): 1267-1274. doi: https://doi.org/10.20546/ijcmas.2019.801.134 